\title{
Determination of silver in layered monocrystals of thermoelectric tellurides by graphite furnace atomic absorption spectrometry
}

\author{
J. Šrámková*, S. Kotrlý, M. Pěknicová \\ Department of Analytical Chemistry, University of Pardubice, 53210 Pardubice, Czech Republic
}

\begin{abstract}
Critical assessment of the processes affecting the atomization of silver in graphite tube helped to develop a precise and reliable method applicable for interpretation of the silver content in telluride materials in relation to their thermoelectric coefficients. While milligram samples of bismuth telluride were easily dissolved in dilute nitric acid, for samples of bismuth antimony telluride an addition of hydrochloric acid was necessary. Tartaric acid was then added, not only to prevent hydrolysis but also to serve as a chemical modifier in graphite furnace AAS determination of Ag at $328.1 \mathrm{~nm}$. Over the range of 0.5 to $7.5 \mathrm{ng} \mathrm{ml}^{-1} \mathrm{of}^{-}$ $\mathrm{Ag}$ the linear calibrations were obtained with a good and long-run reproducibility. A $3 \sigma$ limit of detection for $20 \mu 1$ aliquots was of the order of $0.1 \mathrm{ng} \mathrm{ml}^{-1}$.
\end{abstract}

Keywords. Determination of silver - bismuth antimony telluride - thermoelectric material - atomic absorption spectrometry graphite furnace - matrix modifier.

\section{Introduction}

In the past three decades electrothermal atomic absorption spectrometry (ETAAS) has become a frequently used technique in the trace analysis of silver. Though the number of references has exceeded more than a hundred at present ( $c f$. a review [1]), only a brief account can be found in available monographs (e.g. see [2]). A major part of work has been done in the field of analysis of geological materials, rocks, soils, surface and waste waters. Relatively smaller attention has been given to the analysis of high-purity metals, biological and other materials. For most cases the sensitivity achieved with the use of atomization in graphite furnace was sufficiently high at the wavelength $328.1 \mathrm{~nm}$.

Studies of chemical reactions taking place in the graphite furnace revealed that the complexity of processes was influenced not only by the sample matrix but also by the quality of the graphite tube surface. Experiments indicated that the appearance of free $\mathrm{Ag}$ atoms in the vapour phase was preceded by formation of free metal from a nitrate matrix during the pyrolysis [3]. For silver, the vaporization rate was found to be strongly dependent on the temperature and was higher for pyrolytic graphite-coated graphite tubes [4]. The reaction mechanism of metal release was also affected by the presence of chemisorbed oxygen [5] and was also influenced by carbon monoxide produced in presence of a nitrate matrix. The amount of generated $\mathrm{CO}$ was much greater with an uncoated graphite tube [6].
The influence of the graphite surface was, therefore, investigated more closely. A higher efficiency of atomization, observed with pyrolytic graphite-coated graphite tubes, was attributed to a smaller number of active sites on the inner surface, at which the analyte could be retained [7]. Thus, a sharper peak observed with atomization of Ag was explained by a negligible formation of carbide with carbon atoms on the wall of such pyrocoated tube [8]. The graphite tube after multiple use was investigated by radiography in relation to worsened peak shapes and increased memory effects of the tube $[9,10]$.

The signal depression observed in presence of hydrochloric acid, chloride or other halides was studied in more detail [11-13]. This effect was explained by reactions which took place at relatively low temperatures and affected the volatilization of silver. The introduction of carbonaceous species into the atomization vapour phase, for example by addition of ascorbic acid, glucose, etc., helped to eliminate some matrix effects [14]. Similarly, the use of ammonium salt of EDTA as a modifier additive was effective for the removal of halide interference [11].

Electrothermal AAS (ETAAS) has also found application in the field of analysis of semiconductors. After a thermal pre-treatment of gallium arsenide to remove arsenic, it was possible to determine silver at a level of $4 \mathrm{Ag}$ atoms per $10^{8}$ atoms of the matrix [15]. Direct ETAAS was used for the determination of silver in milligram samples of cadmium selenide [16] and cadmium mercury(II) telluride [17-19].

\footnotetext{
* Correspondence and reprints
}

Received June 15, 1999; revised December 12, 1999; accepted December 14, 1999. 


\section{Original articles}

The aim of this study was to investigate the applicability of graphite furnace AAS not only as a reference procedure to confirm the results of flame AAS (FAAS) [20,21] but also as a reliable method for lower contents of $\mathrm{Ag}$ in milligram samples of layered monocrystals and, if necessary, for investigation of the silver distribution in the crystal. As shown in previous cases of analysis of crystal chips doped with other elements, for example with $\mathrm{Tl}$ [22], the attainable precision and reliability of the method should be adequate to allow a safe correlation of the dopant content with the physical thermoelectric coefficients. The present study was thus motivated by need to provide sufficient data for the interpretation of the effect of the introduction of silver atoms to a crystal lattice with tetradymite structure, which brought about changes in the free carrier concentration [23].

\section{Materials and methods}

\section{Instrumentation}

A Zeiss AAS 3 atomic absorption spectrometer was equipped with an EA 30 graphite furnace (Carl Zeiss, Jena, Germany). For wall atomization pyrolytic graphite-coated graphite tubes (Elektrokohle, Lichtenberg, Germany) were used. The temperature programme for the determination of $\mathrm{Ag}$ is given in table I.

A hollow-cathode lamp for Ag (Cathodeon, England) was operated at $4 \mathrm{~mA}$. The working wavelength of a line Ag $328.1 \mathrm{~nm}$ with a slit width setting of $0.5 \mathrm{~nm}$ and the single beam mode with deuterium background correction for both peak-height and integrated absorbance measurements were used.

A micropipette for a fixed volume of $20 \mu$ l (Labpipette type, Labsystems, Helsinki, Finland) was used to inject sample aliquots. A micrometer operated piston microburette (type PK 2500, University of Pardubice) was used to realize a modified standard addition technique.

\section{Reagents}

Stock standard solution was prepared by dissolving an appropriate accurately weighed mass of analytical-reagent grade $\mathrm{AgNO}_{3}$ (Lachema, Brno, Czech Republic), which was then acidifed to obtain a final acidity of $0.002 \mathrm{M} \mathrm{HNO}_{3}$ and diluted to $1000 \mathrm{ml}$. Working standard solutions ( $c f$. table II) were obtained by appropriate dilution.

For preparation of sample and stock solutions semiconductor-grade $\mathrm{HNO}_{3}$ and analytical grade $\mathrm{HCl}$ (Lachema) were used. All other reagents were of the highest purity available, but the resulting media of standard or sample solutions were checked systematically by parallel running blank tests. Water was purified with the use of a Milli-Q waterpurification system (Millipore, Bedford, MA, USA).

\section{Sample treatment}

In contrast to powdered bismuth telluride which was specially synthesized to be obtained in a polycrystalline form with a defined content of silver (see table III), the monocrystals of $\mathrm{Bi}_{2} \mathrm{Te}_{3}, \mathrm{Bi}_{1.5} \mathrm{Sb}_{0.5} \mathrm{Te}_{3}$ and $\mathrm{BiSbTe}_{3}$ doped with $\mathrm{Ag}$ had a layered structure which allowed them to be easily split along the axis of the crystal cone to about $1 \mathrm{~mm}$ thin plates. From a chosen area of such crystal splitting a rectangular piece (about $3 \mathrm{~mm} \times 12 \mathrm{~mm}$ or less) was cut out and adjusted with contacts for physical measurements. After that it was available for the chemical analysis. As discussed elsewhere in detail $[24,25]$, an actual choice of sample was influenced by the available mass of the crystal chip and the sensitivity of the chosen analytical method.

Samples of powdered material and the monocrystal chips of bismuth telluride (1-2 mg) were dissolved in $2 \mathrm{M} \mathrm{HNO}_{3}$. The dissolution was completed after about $10 \mathrm{~min}$, only for the powdered materials (denoted as BiP in table III) it took 30-60 min of moderate boiling, which was caused by a rather slow oxidation of tellurium to telluric acid. After cooling, the solution was adjusted according to a chosen final volume with $2 \mathrm{M} \mathrm{HNO}_{3}$ to obtain a final acidity of about $0.2 \mathrm{M} \mathrm{HNO}_{3}$.

The monocrystals containing antimony were dissolved in $1 \mathrm{ml}$ of $\mathrm{HNO}_{3}(1+1)$ plus $0.3 \mathrm{ml} \mathrm{HCl}(1+1)$. In contrast with the former case of using only dilute nitric acid, a complete dissolution was achieved within 1-3 min of boiling. After cooling, $0.1 \mathrm{~g}$ of tartaric acid was added, the solution was acidified with $8 \mathrm{ml}$ of $2 \mathrm{MHNO}_{3}$, transferred to a $100 \mathrm{ml}$ standard flask, and diluted with $0.01 \mathrm{M} \mathrm{HNO}_{3}$ to the

Table I. Graphite furnace temperature programme for Ag.

\begin{tabular}{|c|c|c|c|c|c|c|}
\hline & \multicolumn{2}{|c|}{ Drying } & \multicolumn{2}{|c|}{ Pyrolysis } & Atomization & Cleaning \\
\hline \multicolumn{7}{|c|}{ Programme for a medium of $0.24 \mathrm{M} \mathrm{HNO}_{3}, 0.02 \mathrm{M} \mathrm{HCl}$, and $0.007 \mathrm{M}$ tartaric acid } \\
\hline Instrumental settings for step & 1 & 2 & 3 & 4 & 5 & 6 \\
\hline Temperature $\left({ }^{\circ} \mathrm{C}\right)$ & 90 & 110 & 380 & 400 & 1900 & 2500 \\
\hline Ramp time (s) & 18 & 7 & 3 & 0.5 & 0.75 & 0.6 \\
\hline Hold time (s) & 0 & 5 & 2 & 4 & 3 & 3 \\
\hline Internal flow rate of $\mathrm{Ar}\left(\mathrm{ml} \mathrm{min}{ }^{-1}\right)$ & 180 & 180 & 180 & 0 & 0 & 280 \\
\hline
\end{tabular}


Table II. Linear regression analysis of absorbance readings $\left(A \times 10^{3}\right.$ or $A-s \times 10^{3}, k$ calibration solutions, $n$ measurements $)$ versus the analyte concentrations $\left[\mathrm{m}(\mathrm{Ag}) / \mathrm{ng} \mathrm{ml}^{-1}\right]$ for different matrices and methods: $A \times 10^{3}=a+b \mathrm{~m}(\mathrm{Ag})$.

\begin{tabular}{|c|c|c|c|c|c|c|c|c|c|c|}
\hline \multicolumn{3}{|c|}{$\begin{array}{c}\text { Composition of solutions } \\
\qquad\left(H^{+}\right)\end{array}$} & \multicolumn{3}{|l|}{ Method } & \multicolumn{3}{|c|}{ Regression line data } & \multirow[b]{2}{*}{$\begin{array}{c}\text { Blank } \\
\left(A \times 10^{3}\right)\end{array}$} & \multirow[b]{2}{*}{$\begin{array}{c}m_{p} \\
(p g) *\end{array}$} \\
\hline No. & $\begin{array}{c}c\left(H^{+}\right) \\
\left(\mathrm{mol} \mathrm{l}^{-1}\right)\end{array}$ & Acid & Sample matrix & & $k / n$ & $\begin{array}{c}\text { Slope } \\
b\end{array}$ & $\begin{array}{c}\text { Intercept } \\
a\end{array}$ & $s_{y x}$ & & \\
\hline \multirow[t]{2}{*}{1} & \multirow[t]{2}{*}{$0.01^{\mathrm{a}}$} & \multirow[t]{2}{*}{$\mathrm{HNO}_{3}$} & \multirow[t]{2}{*}{$\mathrm{Bi}_{2} \mathrm{Te}_{3}$} & \multirow[t]{2}{*}{ Calibration } & \multirow[t]{2}{*}{$7 / 35$} & $83.3 \pm 1.6^{\mathrm{ph}}$ & 9.0 & 6.0 & 4.9 & \multirow[t]{2}{*}{1.0} \\
\hline & & & & & & $23.5 \pm 0.4^{\mathrm{pa}}$ & 2.5 & 1.5 & 1.3 & \\
\hline \multirow[t]{2}{*}{2} & \multirow[t]{2}{*}{$0.2^{\mathrm{a}}$} & \multirow[t]{2}{*}{$\mathrm{HNO}_{3}$} & \multirow[t]{2}{*}{$\mathrm{Bi}_{2} \mathrm{Te}_{3}$} & \multirow[t]{2}{*}{ Calibration } & \multirow[t]{2}{*}{$7 / 35$} & $95.4 \pm 2.9^{p h}$ & 26.2 & 11.0 & 22.3 & \multirow[t]{2}{*}{0.9} \\
\hline & & & & & & $27.2 \pm 1.0^{\mathrm{pa}}$ & 5.0 & 4.0 & 6.0 & \\
\hline \multirow[t]{2}{*}{3} & \multirow[t]{2}{*}{$0.2^{\mathrm{a}}$} & \multirow[t]{2}{*}{$\mathrm{HNO}_{3}$} & \multirow[t]{2}{*}{$\mathrm{Bi}_{2} \mathrm{Te}_{3}$} & \multirow[t]{2}{*}{ Calibration } & \multirow[t]{2}{*}{$5 / 25$} & $80.5 \pm 3.8^{\mathrm{ph}}$ & 38.1 & 11.8 & 19.7 & \multirow[t]{2}{*}{1.1} \\
\hline & & & & & & $26.0 \pm 1.2^{\text {pa }}$ & 10.5 & 3.7 & 4.9 & \\
\hline \multirow[t]{2}{*}{4} & \multirow[t]{2}{*}{$0.27^{\mathrm{b}}$} & \multirow[t]{2}{*}{$\mathrm{HNO}_{3}$-HCl-tart } & \multirow[t]{2}{*}{$\mathrm{Bi}_{1.5} \mathrm{Sb}_{0.5} \mathrm{Te}_{3}$} & \multirow[t]{2}{*}{ Calibration } & \multirow[t]{2}{*}{$5 / 25$} & $85.4 \pm 2.9^{p h}$ & 30.4 & 9.1 & 27.1 & \multirow[t]{2}{*}{1.0} \\
\hline & & & & & & $27.7 \pm 1.1^{\mathrm{pa}}$ & 9.7 & 3.6 & 8.7 & \\
\hline \multirow[t]{4}{*}{5} & \multirow[t]{4}{*}{$0.27^{\mathrm{b}}$} & \multirow[t]{4}{*}{$\mathrm{HNO}_{3}$-HCl-tart } & \multirow[t]{4}{*}{$\mathrm{Bi}_{1.5} \mathrm{Sb}_{0.5} \mathrm{Te}_{3}$} & Calibration & $7 / 35$ & $84.5 \pm 1.5^{\mathrm{ph}}$ & 24.3 & 6.9 & 4.6 & 1.0 \\
\hline & & & & & & $25.3 \pm 0.5^{\mathrm{pa}}$ & 5.3 & 2.3 & 1.1 & \\
\hline & & & & Stand. Addition & $4 / 20$ & $79.4 \pm 4.8^{p h}$ & - & 8.7 & 5.8 & - \\
\hline & & & & & & $23.1 \pm 1.9^{p a}$ & - & 3.5 & 0.8 & \\
\hline
\end{tabular}

The symbol $s_{y x}$ represents an estimate of the standard deviation of scatter around the regression line.

* The characteristic mass $m_{\mathrm{p}}$ of $\mathrm{Ag}$ in pg per a $20 \mu \mathrm{l}$ injection corresponds to a conventional increase in absorbance of 0.0044 .

The concentration of working standard silver solutions $\left(\mathrm{Ag}, \mathrm{ng} \mathrm{ml}^{-1}\right)$ : ${ }^{\mathrm{a}} 25.20{ }^{\text {b }} 30.215$

The analytical signal was measured as: ${ }^{\text {ph }}$ peak height absorbance; ${ }^{\text {pa }}$ integrated peak-area absorbance

mark; the resulting concentrations of the acids were $0.24 \mathrm{M} \mathrm{HNO}_{3}, 0.02 \mathrm{M} \mathrm{HCl}$, and $0.0067 \mathrm{M}$ tartaric acid.

\section{Application of the technique of standard additions}

The method of standard additions was modified in order to achieve a defined increase of the measured signal in three steps. Three $10 \mathrm{ml}$ aliquots were transferred to 3 dry $25 \mathrm{ml}$ beakers provided with a small magnetic stirrer and to each one the relevant volume, for example $0.20,0.40$ and $0.60 \mathrm{ml}$, respectively, of a standard silver solution $\left(m_{\mathrm{Ag}}=30.41 \mathrm{ng} \mathrm{ml}^{-1}\right)$ was delivered from a calibrated microburette. Corrections for the dilution should be made for both the absorbance readings and the concentration increase. A Quattro Pro program, which implemented linear regression and all essential statistical evaluations, was used in course of the present work [26].

\section{Results and discussion}

\section{Pyrolysis and atomization from different media}

For investigation of the processes taking place in the graphite tube the composition of sample solutions had to be taken into consideration, as resulted from the nature of the telluride thermoelectric material and the procedure used for the sample treatment. By dissolving silver-doped bismuth telluride in dilute nitric acid a sample solution containing $\mathrm{Bi}^{3+}, \mathrm{Ag}^{+}$and $\mathrm{H}_{2} \mathrm{TeO}_{3}$ in approx. $0.2 \mathrm{M} \mathrm{HNO}_{3}$ was obtained. A more complicated solution was obtained by dissolving bismuth antimony telluride, because in this case an addition of
$\mathrm{HCl}$ was necessary to help the dissolution of the monocrystal and then tartaric acid had to be added to prevent hydrolysis of antimony(III). In addition to the above-given species, the sample solution contained complexes of $\mathrm{Sb}$ (III) and chloro complexes of $\operatorname{Ag}(\mathrm{I})$. It was realized that the thermal pre-treatment, which involves complicated processes of thermal decomposition, had a decisive influence on the result of the subsequent atomization step.

In an apparently simple case of silver(I) in medium of only dilute nitric acid, the process of drying at $90-110^{\circ} \mathrm{C}$ leaves a residue of $\mathrm{AgNO}_{3}$ which melts (m.p. $209.8^{\circ} \mathrm{C}$ ) before it begins to be decomposed. The melt may partially penetrate into microscopical cracks of the graphite surface. The thermal decomposition starts above $250{ }^{\circ} \mathrm{C}$ to yield $\mathrm{AgNO}_{2}$ and then continues at $400-450{ }^{\circ} \mathrm{C}$ to metallic silver with evolution of nitrogen oxides, oxygen and nitrogen (the data on temperatures and reactions given here were taken from literature on inorganic chemistry, e.g. [27]; for a complete conversion to silver metal $740 \mathrm{~K}$ was also reported [3]). It is not a calm process. When a large amount of silver nitrate was decomposed thermally by drying and charring (steps 1-4 in table I) in one of our experiments, silvercontaining particles were found by electron microprobe to be scattered at the end of graphite tube in form of a ring deposit.

Formation of chloro complexes in the presence of $\mathrm{HCl}$ helps to keep traces of silver(I) in solution; on heating they are decomposed and a residue of silver chloride (m.p. $455^{\circ} \mathrm{C}$ ) resists till the step of atomization.

As shown previously in the case of thallium [22], an addition of tartaric acid changed entirely the reaction mechanism 


\section{Original articles}

Table III. Silver content in thermoelectric tellurides $\mathrm{Bi}_{2-x} \mathrm{Ag}_{\mathrm{x}} \mathrm{Te}_{3}$ and $\left(\mathrm{Bi}_{m} \mathrm{Sb}_{n}\right)_{2-x} \mathrm{Ag}_{x} \mathrm{Te}_{3}$.

\begin{tabular}{|c|c|c|c|c|c|}
\hline $\begin{array}{l}\text { Sample* } \\
N_{o}\end{array}$ & Code & $\begin{array}{l}\text { Taken } \dagger \\
(\mathrm{mg} / \mathrm{ml})\end{array}$ & $\begin{array}{c}\text { Absorbance } \ddagger \\
\left(10^{3} \times A\right)\end{array}$ & $\begin{array}{l}\text { Ag found } \\
\text { Solution } \$ \\
\left(\mathrm{ng} \mathrm{ml}^{-1}\right)\end{array}$ & $\begin{array}{c}\text { Solid } \\
\text { sample } \$ \\
(\text { ppm })\end{array}$ \\
\hline 1 & BiPAg02 & $1.296 / 500$ & $\begin{array}{l}96.4^{\mathrm{ph}} \\
24.3^{\mathrm{pa}}\end{array}$ & $\begin{array}{l}0.97 \pm 0.12 \\
0.93 \pm 0.09\end{array}$ & $\begin{array}{l}374 \pm 46 \\
358 \pm 37\end{array}$ \\
\hline 2 & BiPAg06 & $1.780 / 1000$ & $\begin{array}{c}254.3^{\mathrm{ph}} \\
69.8^{\mathrm{pa}}\end{array}$ & $\begin{array}{l}2.63 \pm 0.08 \\
2.60 \pm 0.14\end{array}$ & $\begin{array}{l}1475 \pm 46 \\
1461 \pm 79\end{array}$ \\
\hline 3 & BiPAg10 & $2.081 / 250$ & $\begin{array}{r}180.2^{\mathrm{ph}} \\
48.4^{\mathrm{pa}}\end{array}$ & $\begin{array}{l}1.85 \pm 0.11 \\
1.81 \pm 0.16\end{array}$ & $\begin{array}{l}222 \pm 14 \\
218 \pm 19\end{array}$ \\
\hline 4 & BiPAg35 & $1.301 / 2500$ & $\begin{array}{l}153.4^{\mathrm{ph}} \\
41.4^{\mathrm{pa}}\end{array}$ & $\begin{array}{l}1.57 \pm 0.06 \\
1.56 \pm 0.07\end{array}$ & $\begin{array}{l}3011 \pm 115 \\
2994 \pm 138\end{array}$ \\
\hline 5 & $\mathrm{BiAg} 20$ & $2.190 / 400$ & $\begin{array}{r}117.1^{\mathrm{ph}} \\
33.0^{\mathrm{pa}}\end{array}$ & $\begin{array}{l}1.19 \pm 0.09 \\
1.25 \pm 0.08\end{array}$ & $\begin{array}{l}217 \pm 16 \\
228 \pm 14\end{array}$ \\
\hline 6 & BiAg35 & $1.142 / 500$ & $\begin{array}{l}93.0^{\mathrm{ph}} \\
28.2^{\mathrm{pa}}\end{array}$ & $\begin{array}{l}0.93 \pm .0 .04 \\
1.07 \pm 0.07\end{array}$ & $\begin{array}{l}409 \pm 19 \\
469 \pm 31\end{array}$ \\
\hline 7 & $\mathrm{Sb} 0.5 \mathrm{Ag} 05 \mathrm{~B}$ & $1.241 / 100$ & $\begin{array}{c}86.7^{\mathrm{ph}} \\
24.9^{\mathrm{pa}} \\
78.6^{\mathrm{StAph}} \\
22.8^{\mathrm{StApa}}\end{array}$ & $\begin{array}{l}0.79 \pm 0.04 \\
0.82 \pm 0.06 \\
0.78 \pm 0.04 \\
0.75 \pm 0.03\end{array}$ & $\begin{array}{l}64.0 \pm 2.8 \\
66.0 \pm 4.6 \\
63.2 \pm 3.2 \\
60.4 \pm 2.7\end{array}$ \\
\hline 8 & Sb0.5Ag15C & $1.495 / 100$ & $\begin{array}{l}487.6^{\mathrm{ph}} \\
144.0^{\mathrm{pa}}\end{array}$ & $\begin{array}{l}5.54 \pm 0.28 \\
5.53 \pm 0.36\end{array}$ & $\begin{array}{l}370 \pm 19 \\
370 \pm 24\end{array}$ \\
\hline 9 & Sb1.0Ag05 & $1.133 / 100$ & $\begin{array}{c}143.0^{\mathrm{ph}} \\
42.7^{\mathrm{pa}} \\
136.2^{\mathrm{StAph}} \\
40.6^{\mathrm{StApa}}\end{array}$ & $\begin{array}{l}1.46 \pm 0.02 \\
1.52 \pm 0.12 \\
1.72 \pm 0.03 \\
1.76 \pm 0.05\end{array}$ & $\begin{array}{c}129 \pm 1.5 \\
135 \pm 10.5 \\
151 \pm 2.5 \\
155 \pm 4.3\end{array}$ \\
\hline 10 & Sb1.0Ag15A & $1.365 / 100$ & $\begin{array}{l}394.8^{\mathrm{ph}} \\
111.2^{\mathrm{pa}}\end{array}$ & $\begin{array}{l}4.44 \pm 0.02 \\
4.23 \pm 0.07\end{array}$ & $\begin{array}{l}325 \pm 1.2 \\
310 \pm 4.9\end{array}$ \\
\hline & & $\begin{array}{l}1.365 / 500^{\mathrm{a}} \\
1.365 / 500^{\mathrm{a}}\end{array}$ & $\begin{array}{l}89.5^{\mathrm{ph}} \\
25.6^{\mathrm{pa}} \\
93.5^{\mathrm{ph}} \\
29.0^{\mathrm{pa}}\end{array}$ & $\begin{array}{l}0.83 \pm 0.07 \\
0.85 \pm 0.13 \\
0.87 \pm 0.11 \\
0.98 \pm 0.06\end{array}$ & $\begin{array}{l}302 \pm 27 \\
310 \pm 47 \\
320 \pm 39 \\
359 \pm 21\end{array}$ \\
\hline 11 & Sb1.0Ag15B & $\begin{array}{l}1.788 / 100 \\
1.788 / 500^{\mathrm{a}}\end{array}$ & $\begin{array}{r}593.1^{\mathrm{ph}} \\
192.6^{\mathrm{pa}} \\
141.4^{\mathrm{ph}} \\
42.9^{\mathrm{pa}}\end{array}$ & $\begin{array}{l}6.79 \pm 0.34 \\
7.45 \pm 0.18 \\
1.44 \pm 0.03 \\
1.53 \pm 0.05\end{array}$ & $\begin{array}{l}380 \pm 19 \\
417 \pm 10 \\
402 \pm 8.9 \\
428 \pm 14\end{array}$ \\
\hline
\end{tabular}

* Sample code: the first symbol denotes a metal component of a telluride monocrystal, $\mathbf{B i}_{2-x} \mathrm{Ag}_{x} \mathrm{Te}_{3}$ or $\left(\mathrm{Bi}_{m} \mathbf{S b}_{\mathrm{n}}\right)_{2-x} \mathrm{Ag}_{x} \mathrm{Te}_{3}$; a subsequent number specifies the stoichiometric coefficient of $\mathrm{Sb}(2 n)$; letter P denotes a polycrystalline material with nearly homogeneous distribution of silver; the coefficient after Ag is equal to $1000 x$; the following letter $\mathrm{A}-\mathrm{C}$ denotes subsequent locations of small samples taken along a particular crystal chip.

$\dagger$ The composition of sample solutions corresponded to those resulting with the use of recommended procedures ( $c f$. table II, $\mathrm{N}^{\circ} 3$ and 5 ); ${ }^{\text {a }}$ replicate dilution.

$\ddagger$ An average of absorbance $(n=5)$ for measurements: ph peak height; pa integrated peak area; StA the same sample solution with application of a modified standard additions technique.

$\S$ The average value with a $95 \%$ confidence interval.

of the thermal pre-treatment. During the step of drying volatile mineral acids were removed completely, because the metal species resulting from the telluride material were converted to tartarato complexes. As some metal tellurites form insoluble precipitates when acidity of a solution becomes low, the dry residue may contain yellowish metal tellurites. For example, for the stoichiometric solubility product of $\mathrm{Ag}_{2} \mathrm{TeO}_{3}, K_{\mathrm{s}}=[\mathrm{Ag}]^{2}\left[\mathrm{TeO}_{3}\right]$, a value $-\log K_{\mathrm{s}}=17.85 \pm 0.11$ (for $\log K_{\mathrm{H}}\left(\mathrm{H}_{2} \mathrm{TeO}_{3}\right)=2.52, \log K_{\mathrm{H}}\left(\mathrm{HTeO}_{3}{ }^{-}\right)=7.70 ; 25^{\circ} \mathrm{C}$ ) was reported [28]. It is known, however, that silver(I) is easily reduced to the metallic form in the presence of tartaric acid. At about $300{ }^{\circ} \mathrm{C}$ tartaric acid begins to be decomposed quietly to a carbonaceous residue and volatile vapours of tar; these products also take part in the redox reactions of pyrolysis and atomization ( $c f .[22])$.
The dependence of the absorbance signal on temperature for the step of pyrolysis (see figure 1) reached a maximum about $400{ }^{\circ} \mathrm{C}$, which supported the interpretation given above. The corresponding part of the temperature programme (table I, separation of steps 3 and 4 is necessary for the spectrometer operation) represents an optimum choice considering both the signal value and the shape of the peak which was obtained in an ideal form of a sharp gaussian curve. Minimum temperature that was required to produce a detectable release of atomic vapour $\mathrm{Ag}_{(\mathrm{g})}$ from metallic $\mathrm{Ag}_{(\mathrm{s})}$ was reported as low as $680{ }^{\circ} \mathrm{C}$ [3], which might explain lowering of the absorbance signal observed at higher temperatures of the pyrolysis (Fig. 1). 


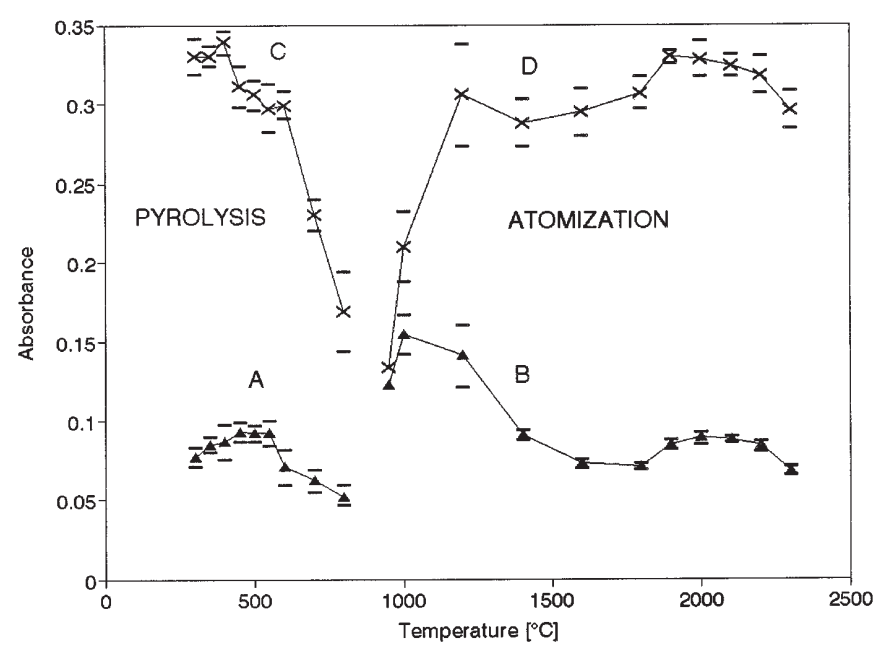

Fig. 1. Temperature dependence of the absorbance signal for the pyrolysis (with atomization at $1900{ }^{\circ} \mathrm{C}$ ) and the atomization (with pyrolysis at $400{ }^{\circ} \mathrm{C}$ ) obtained with $20 \mu \mathrm{l}$ injections of $\mathrm{Ag}(61 \mathrm{pg})$ and for a medium of $0.24 \mathrm{M} \mathrm{HNO}_{3}, 0.02 \mathrm{M} \mathrm{HCl}$, and $0.007 \mathrm{M}$ tartaric acid with a $5 \mu$ mol ${ }^{-1}$ BiSbTe $_{3}$ matrix: $A, B$ integrated peak area absorbance; $C, D$ peak height absorbance $(n=5$ at each temperature setting; average values shown with $95 \%$ confidence intervals).

Temperature dependence of the atomization signal showed a steep increase about $1000{ }^{\circ} \mathrm{C}$ to reach a maximum about $1200{ }^{\circ} \mathrm{C}$, where the transient absorbance formed a broad maximum extending over the whole period of the atomization step, as indicated also by the corresponding values of integrated peak area absorbance; thus this atomization temperature region was not at all suitable for the determination of silver. A typical shape of gaussian transient peak began to be formed at $1400{ }^{\circ} \mathrm{C}$. In order to find an optimum atomization temperature the stability of the signal was also taken into account. The tube temperature of $1900{ }^{\circ} \mathrm{C}$ was thus used for further experiments ( $c f$. b.p. $2212{ }^{\circ} \mathrm{C}$ for $\mathrm{Ag}$ metal). The chosen temperature was close to most spectrometer cookbook information. At higher atomization temperatures the transient absorbance showed a tendency to be overcompensated.

\section{Influence of different matrix media}

The procedure with the temperature programme listed in table I was tested for different composition of analyte solutions, as listed with figure 2 . The results illustrate relative positions of averages evaluated $(A-G)$ for several series of peak height measurements together with $95 \%$ confidence intervals. Optimization of the analytical procedure for the samples of Bi-Sb-Te materials $(E)$ was well reproducible and an average of 23 determinations of $\mathrm{Ag}$ was chosen for a reference value of $100 \%$. The results for purely nitric acid medium were lower of about $15 \%$ (compare $A$ with $E$ ) and, as also shown by the two confidence intervals, this decrease was statistically significant. The addition of tartaric acid

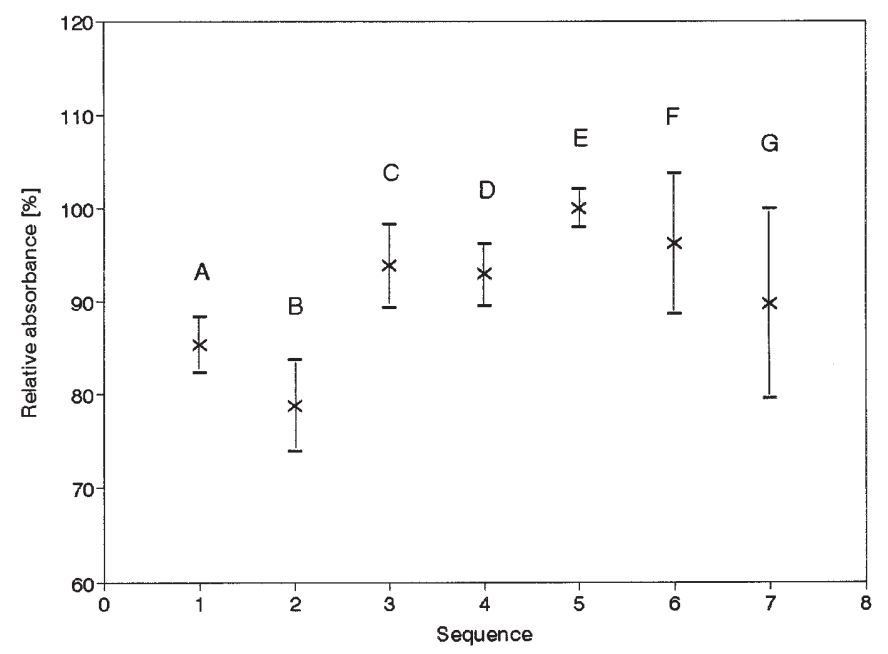

Fig. 2. Determination of $\mathrm{Ag}$ ( $48 \mathrm{pg}$ per $20 \mu \mathrm{l}$ injection) in different media. The error bars indicate relative position of averages of peak height absorbance with $95 \%$ confidence intervals $v s$. the recommended procedure $(\mathrm{E} \sim 100 \%)$. Composition of solutions: mineral acids: $A 0.24 \mathrm{M} \mathrm{HNO}_{3}$ only; $B-F 0.24 \mathrm{M} \mathrm{HNO}_{3}, 0.02 \mathrm{M}$ $\mathrm{HCl}$; decomposed telluride $D 5 \times 10^{-6} \mathrm{M} \mathrm{Bi}_{2} \mathrm{Te}_{3} ; E-G 1.3 \times 10^{-6}$ $\mathrm{M} \mathrm{Bi}_{1.5} \mathrm{Sb}_{0.5} \mathrm{Te}_{3}$; matrix modifier $E 6.7 \times 10^{-3}$ or $13.3 \times 10^{-3} \mathrm{M}$ tartaric acid; $F-G 13.3 \times 10^{-3} \mathrm{M}$ tartaric acid, $22.7 \times 10^{-3} \mathrm{M}$ ascorbic acid, $G$ with addition of $11.7 \times 10^{-3} \mathrm{M} \mathrm{Mg}\left(\mathrm{NO}_{3}\right)_{2}$. Number of experiments, $n$ : $A$ 14; $B$ 14; $C 15 ; E 23 ; F 5 ; G 5$.

helped to remove the interfering effect of chloride ( $c f . B$ ) which caused lowering of the signal. This might be interpreted by such a high affinity of chloride to $\mathrm{Ag}(\mathrm{I})$ that some $\mathrm{AgCl}$ species survive $\left(1550{ }^{\circ} \mathrm{C}\right.$ is b.p. of $\left.\mathrm{AgCl}\right)$ even at the beginning of the atomization step. The addition of tartaric acid eliminated thus the interference of chloride $(c f . C$ and see [22] for detailed discussion on effects of chemical modifiers).

It is interesting that a substantially higher result of about $93 \%$ was obtained with a nitric acid solution in the presence of bismuth tellurite matrix $(D)$. The modifying effect of tellurite in combination with tartaric acid caused that the shapes of transient absorbance peaks were ideally symmetrical and very sharp $(E)$. When the addition of tartaric acid was doubled (to $0.1 \mathrm{~g}$ per $50 \mathrm{ml}$ ), no statistically important difference was observed (with the use of a $t$-test at $95 \%$ probability). However, a further concentration increase of carbonaceous substance, such as ascorbic acid (cf. F), brought about a certain scatter of the analytical signal. The effect of a magnesium containing chemical modifier ( $c f$. ref. [22]), which caused lower and even more scattered results $(c f . G)$ with the applied temperature programme, is worth of a further investigation for some different sample matrices.

\section{Effect of graphite tube surface}

In the course of determinations of silver over a time-span of nearly three years, sudden deformations of the peak with corresponding decrease of the absorbance were observed 


\section{Original articles}

after more than 100-150 firings were done in a given graphite tube, in contrast with our previous experience with some other dopants ( $\mathrm{Pb}, \mathrm{Tl}, \mathrm{In})$. This was evidently caused by an irreversible change of the graphite surface. With the use of an electron microscope it was possible to observe formation of wider and deeper cracks just below the opening for sample injections. The difference between the surface of a new graphite-coated graphite tube and that of a tube at the end of its life time is shown in figure 3 . The enhanced corrosion with silver containing samples can be explained by formation of melts during the pyrolysis, as discussed in detail above. Melted salt penetrates into microscopic imperfections of the surface and then at a high temperature of atomization these cracks are burnt out with available oxygen of the salt to become wider. This process is evidently increased by presence of silver in comparison with similar samples of other dopants, for example see [22]. A rugged surface causes a delayed vaporization of silver, which is also shown by formation of a tail to the peak.

However, before the deterioration of the tube performance became apparent, the results of the firing of silver were safely reliable. This was shown by the comparison of two series of determinations ( $c f . E$ in figure 2). The first one of 10 firings was performed in a tube in a middle of its life time and gave an average of peak height absorbance of 0.236 . The second series $\left(n_{2}=8\right)$ was performed after about 4 hours with the same sample solution but in a new graphite tube. An absorbance average of 0.227 was obtained. There was no statistically important difference in both the standard deviations and the two averages ( $F$ and $t$-test at $p=0.95)$.

\section{Calibration and linear regression analysis}

The results of the determination of silver by flame atomic absorption spectrometry [21], which was used as a routine screening or preliminary method, were taken into consideration to define the concentration range for the calibration. For each calibration solution a mass of pure $\mathrm{Bi}_{2} \mathrm{Te}_{3}$ and $\mathrm{Bi}_{1.5} \mathrm{Sb}_{0.5} \mathrm{Te}_{3}$, respectively, which corresponded to an average sample mass, was weighed and dissolved, as described above. After cooling, a known volume of the standard silver nitrate solution was added (see table II), which was followed by the addition of tartaric acid, if antimony was present in the matrix, and adjustment of the total acidity. Then, after transferring to a standard flask, the solution was diluted with $0.001 \mathrm{M} \mathrm{HNO}_{3}$ to the mark. Usually five or seven calibration solutions with increasing concentrations of Ag were prepared and from each of them about five replicate $20 \mu \mathrm{l}$ aliquots were taken for firing. For each calibration, a concurrent series of blank tests was run with the use of a solution that contained all components except silver. An average value of five blank test readings was used for the corrections.

Table II lists the data for the regression analysis of some calibrations made in course of one year. In all instances, a straight line equation was adequate to represent the calibration data and, as shown by the data on linear regressions, a good long-run reproducibility was achieved. For an optimum
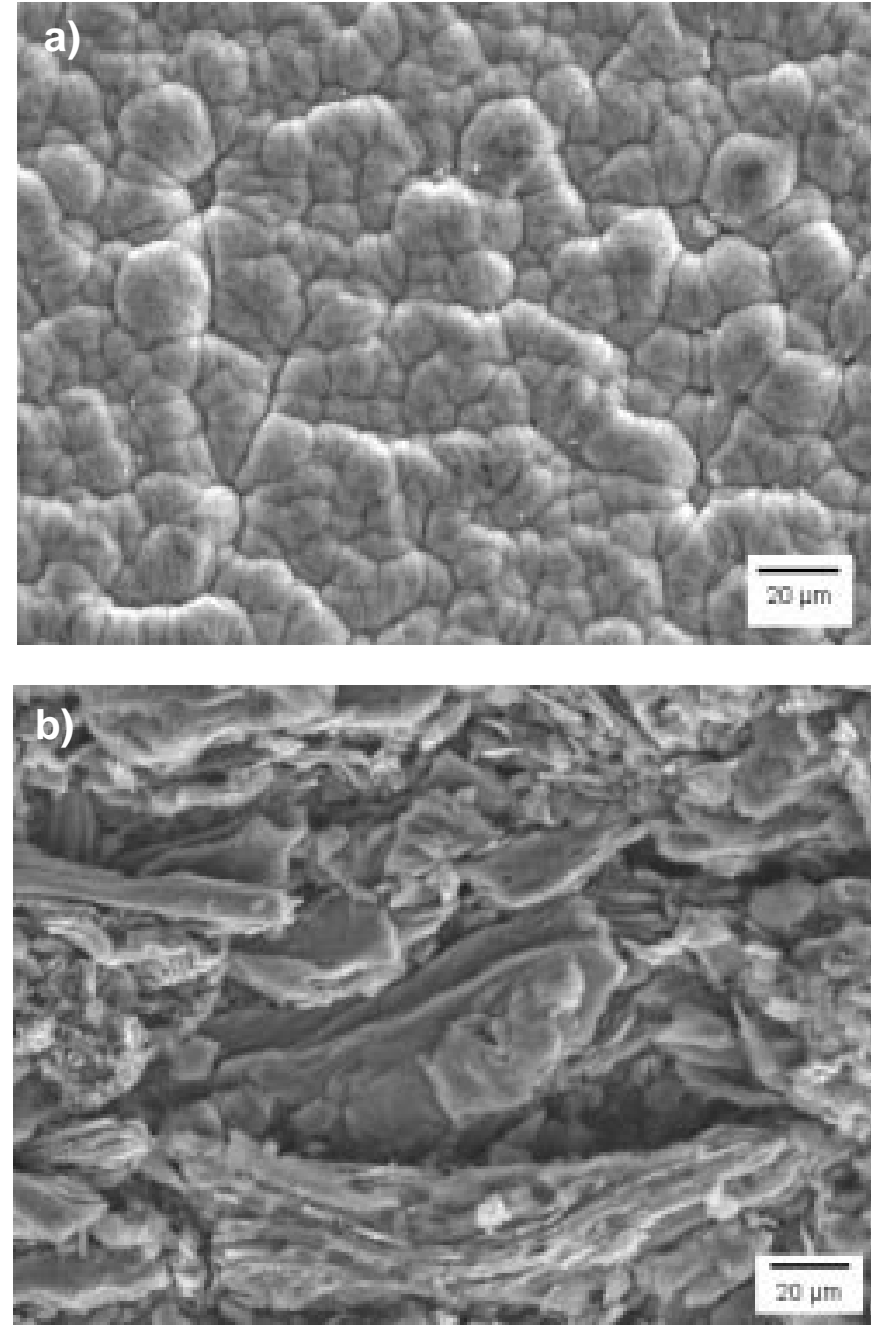

Fig. 3. Electron microscope photograph of inner surface of graphite-coated graphite tube (magnification of 1000) a) new tube in good condition; b) below the injection opening after 200 firings.

experimental realization, as described above, the change in composition of solutions, which resulted for the two types of telluride materials, had no great influence on the calibration lines. The average slope value (for $\mathrm{Bi}_{2} \mathrm{Te}_{3}, \mathrm{~N}^{\circ} 1-3$ ) is practically the same as that for the matrix with antimony $\left(\mathrm{N}^{\circ} 4,5\right)$. Applicable range of the calibration is from 0.5 to $7.5 \mathrm{ng}$ Ag per ml.

The results in table II provide evidence that a good agreement was achieved in repeated calibrations. For example, it can be seen that both the slope and intercept values of the calibrations 4 and 5, which were used for the evaluation of most determinations of $\mathrm{Ag}$ in antimony containing monocrystal chips, were obtained in good agreement. Table II brings also evidence that the applied procedure of standard additions provided a statistically identical slope value $\left(c f . \mathrm{N}^{\circ} 5\right)$. The greatest difference between the slope 
values (see $\mathrm{N}^{\circ} 2$ and 3 ) amount to about $16 \%$. An average value for a conventional increase of 0.0044 in peak height absorbance was evaluated as a concentration of $0.051 \mathrm{ng} \mathrm{ml}^{-1}$ and a characteristic mass $m_{\mathrm{p}}$ of $1 \mathrm{pg} \mathrm{Ag}$ per a $20 \mu \mathrm{l}$ injection.

\section{Determination of silver in layered monocrystals}

The thermoelectric material of silver-doped bismuth telluride and bismuth antimony telluride, respectively, which was grown by a modified Bridgman method [29], had a marked concentration gradient of silver along both the length and width of the resulting monocrystal cone of layered structure. Thus each sample cut out from chosen area of thin crystal splitting represented an individual specimen of a mass in the range of milligrams depending on the size and thickness of the crystal chip. As was realized with previously studied dopants [22,24], the results of the analytical procedure had to be sufficiently precise and reliable, because there is practically no or very limited possibility of replicate assays of a crystal chip, which is influenced by the extent of the dopant segregation.

Powdered bismuth telluride (table III, $N^{\circ} 1-4$ ) was synthesized so that the segregation of added silver was prevented. However, the content of silver was found to be rather high (200-3000 ppm) so that it was necessary to dilute the sample solutions to final volumes given in the table. For most cases the relative standard deviation was in the range $2-5 \%$ and a satisfactory agreement was obtained between the results based both on peak height and peak area measurements and the given amount of $\mathrm{Ag}$ in the powdered samples. The sensitivity of the method was also found to be high for the analysis of crystal chips with silver content $60-430 \mathrm{ppm}$. For a sample mass of 1-2 mg the final sample volume was chosen to obtain absorbance in the range of $0.09-0.6$ and $0.02-0.2$ for peak height and peak area measurement, respectively. As shown with samples $\mathrm{N}^{\circ} 10$ and 11, an additional dilution helped to achieve a closer agreement of results.

The values of parallel reagent blanks were in a range of $0.004-0.022$ and $0.001-0.006$ for peak height and integrated peak area absorbance, respectively. Instrumental instability and, to a smaller extent, a secondary contamination with dust may contribute to the blanks. Statistical tests showed no significant difference between the variance of particular intercept value $a$ and the blank test series. The intercept was always significantly different from zero; therefore, the correction for blank was introduced for all cases.

The variances of the reagent blanks were tested with respect to those for a low absorbance (usually for the first calibration point). If an $F$-test showed no significant difference, a pooled standard deviation was calculated. Thus for such peak height readings corresponding to calibration $\mathrm{N}^{\circ} 5$ in table II a pooled value of $s=A \times 10^{3}$ was 1.1 and hence a $3 s$ estimate of the detection limit of $\mathrm{Ag}$ was $0.04 \mathrm{ng} \mathrm{ml}^{-1}$ or $0.8 \mathrm{pg}$ for an injection of $20 \mu \mathrm{l}$. The same value was obtained for the peak area readings. In order to achieve such result a demanding control of all experimental details was necessary. For more routine work, the detection limit was reproducible at a level of $0.1 \mathrm{ng} \mathrm{ml}^{-1}$.

The sensitivity of peak height measurements with the use of graphite tube was found to be about 1400-times higher than that obtained for a optimum use of flame AAS [21]; however, flame AAS (FAAS) was found to be adequate for routine screening analysis of crystal chips if a sufficiently great mass of sample was available. For example, in the case of sample $\mathrm{N}^{\circ} 8$ in table III, a mass of $14.81 \mathrm{mg}$ was dissolved to obtain $10 \mathrm{ml}$ of sample solution. With the use of FAAS a silver content of $382 \mathrm{ppm}$ was found, in good agreement with the result of $370 \mathrm{ppm}$ for a mass of $1.5 \mathrm{mg}$ dissolved for a $100 \mathrm{ml}$ sample solution. Similarly, the sample $\mathrm{N}^{\circ} 11$ was analyzed also by FAAS $(23.95 \mathrm{mg} / 10 \mathrm{ml})$ and a result of $398 \mathrm{ppm}$ was obtained, which corresponds well with the data given in table III. The method of FAAS failed, however, if the content of $\mathrm{Ag}$ was less than $100 \mathrm{ppm}$ or the available sample mass was small. This was the case of sample $\mathrm{N}^{\circ} 7$, for example, for which even the peak height absorbance was within a low part of the calibration. In such case, the method of repeated standard additions was used when a supporting result was necessary. A modified version of this technique, as described above, allowed to achieve a close agreement with the calibration slope value and provided reliable results even for concentrations approaching a quantification limit $(10 \sigma)$ of $1 \mathrm{ng} \mathrm{ml}^{-1}$.

\section{References}

1. Šrámková, J.; Kotrlý, S. Sci. Pap. Univ. Pardubice, Ser. $A, 1999$ (in print).

2. Welz, B. Atomabsorptions-spektrometrie, $3^{\text {rd }}$ edn, Verlag Chemie, Weinheim, 1983, p 346.

3. Rowston, W.B.; Ottaway, J.M. Analyst, 1979, 104, 645.

4. Wendl, W. Fresenius' Z. Anal. Chem., 1986, 323, 726.

5. Salmon, S.G.; Holcombe, J.A. Anal. Chem., 1982, 54, 630.

6. Frech, W.; Lindberg, A.O.; Lundberg, E.; Cedergen, A. Fresenius' Z. Anal. Chem., 1986, 323, 716.

7. Schlemmer, G.; Welz, B. Fresenius' Z. Anal. Chem., 1986, 323, 703.

8. Zheng, Y.; Xiang, Y. Jilin Daxue Ziran Kexue Xuebao, 1990, (2), 107; Chem. Abstr., 1990, 113, 243709.

9. Belyaev, Y.I.; Khozhainov, Y.M.; Shcherbakov, V.I. Zh. Anal. Khim., 1983, 38, 1135.

10. Belyaev, Y.I.; Khozhainov, Y.M.; Shcherbakov, V.I.; Myasoedov, B.F. Zh. Prikl. Spektrosk., 1984, 41, 831.

11. Matsusaki, K. Anal. Chim. Acta, 1982, 141, 233.

12. Frech, W.; Lundberg, E.; Cedergren, A. Can. J. Spectrosc., 1985, 30, 123.

13. Varga, K.; Kantor, T. Magy Kem. Foly, 1987, 93, 488.

14. Sedykh, E.M.; Belyaev, Y.I.; Sorokina, E.V. Zh. Anal. Khim., 1980, 35, 2348.

15. Gusheina, I.S.; Headridge, J.B.; Johnson, D.; Jackson, K.W.; McLeod, C.W.; Roberts, J.A. Anal. Chim. Acta, 1987, 197, 87.

16. Khozhainav, Y.M.; Tyurin, O.A.; Deinikina, N.P. Zavod Lab. 1985, 51, 30 . 


\section{Original articles}

17. Grainger, F.; Gale, I.G. J. Mater. Sci., 1979, 14, 1370.

18. Zelentsova, L.V.; Kulish, N.G.; Yudelevich, I.G. Zh. Anal. Khim. 1987, 42, 2180.

19. Guenther, H.; Boeck, T.; Frank, C.; Jacobs, K. Fresenius' Z. Anal. Chem. 1992, 343, 756.

20. Šrámková, J.; Kotrlý, S. Sb-Semin At Spektrochem, $13^{\text {th }}$, 1996, 189; Chem. Abstr. 1998, 128, 56813.

21. Šrámková, J.; Kotrlý, S.; Jakoubková, P. Anal. Chim. Acta, in print.

22. Šrámková, J.; Kotrlý, S.; Doležalová, K. J. Anal. At. Spectrom. 1995, 10, 763.
23. Klichová, I.; Lošták, P.; Drašar, Č; Navrátil, J.; Beneš, L.; Šrámková, J. Radiation Effects \& Defects in Solids, 1998, 145, 245.

24. Šrámková, J.; Kotrlý, S. Talanta 1988, 35, 841.

25. Kotrlý, S.; Šrámková, J.; Chadima, R.; Čermák, J. Analyst, 1993, 118, 79.

26. Kotrlý, S.; Šrámková, J. (to be published).

27. Gmelins Handbuch der anorganischen Chemie, Vol B1, $8^{\text {th }}$ Ed., Verlag Chemie, Weinheim, 1971, p. 212.

28. Mehra, M.C.; Kahn, S.M. Can. J. Chem., 1972, 50, 1788.

29. Lošták, P.; Novotný, R.; Beneš, L.; Civiš, S. J. Cryst. Growth, 1989, 94, 656. 